\title{
SUBSTANTIATING THE DIFFUSION MODEL OF INNOVATION IMPLEMENTATION AND ITS APPLICATION TO VACCINE PROPAGATION*
}

\author{
V. M. Gorbachuk, ${ }^{1 \dagger}$ M. S. Dunaievskyi, ${ }^{1+}$ A. A. Syrku, ${ }^{2}$ and S.-B. Suleimanov ${ }^{1 \dagger \dagger} \quad$ UDC 519.8
}

\begin{abstract}
The paper examines prerequisites and assumptions of the classical Bass innovation diffusion model with the aim of applying it in modeling of relevant stochastic processes related to the pandemic. The Bass model has proven its versatility and applicability to various environments. A thorough mathematical substantiation of the model properties is presented based on theories of evolutionary equations and stochastic processes for its further development, as well as search for uncertainty parameters and observable variables. The paper provides realistic estimation results of the Bass model parameters for vaccination in Ukraine and Belarus on weekly data of the first half of 2021. Similar studies are suggested for other countries, as well as regions and districts of Ukraine.
\end{abstract}

Keywords: new product, critical mass, pandemic, marketing, healthcare, stochastic processes.

\section{INTRODUCTION}

Frank M. Bass (1926-2006), the author of the classical model, was the first winner of the William F. O'Dell Award of the American Marketing Association (AMA) in 1979 for his publication [2], the winner of the AMA Paul D. Converse Award (established in 1946) in 1986, the winner of the John DC Little Award (John DC Little was first Doctor of Philosophy rewarded in operations research and the first President of the Institute for Operations Research and the Management Sciences, INFORMS), which was established in 1982, in 1988 for the best management and marketing publication [3] (the publication was published after two revisions), the winner of the Shelby D. Hunt/Harold H. Maynard Award (started in 1974) in 1991 for the best publication in the Journal of Marketing [4] (the publication is a shortened version of the material submitted to journal's editorial board), the winner of the AMA Churchill Award (established in 1996) in 2002, and the winner of the AMA and the Wharton Business School of the University of Pennsylvania (founded in 1881, ranking as the best business school according to Financial Times) Charles Coolidge Parlin Marketing Research Award (established in 1945) in 2003. In 2005, University of South Australia (founded in 1856 and ranked 295th in the QS World University rating in 2021) founded the Ehrenberg-Bass Institute for Marketing Science, and the University of Groningen in the Netherlands (founded in 1614 and ranked 128th in QS the World University rating in 2021) created the Frank M. Bass Chair at the Faculty of Economics and Business.

\footnotetext{
* The research was conducted with a partial support of the National Research Foundation of Ukraine under the project "Analytical methods and machine learning in management theory and decision-making under conflict and uncertainty conditions" (grant No. 2020.02/0121).

${ }^{1}$ V. M. Glushkov Institute of Cybernetics, National Academy of Sciences of Ukraine, Kyiv, Ukraine, ${ }^{\dagger}$ GorbachukVasyl@netscape.net; ${ }^{\ddagger}$ MaxDunaievskyi@gmail.com; ${ }^{\dagger \dagger}$ sbsuleimanov@gmail.com. ${ }^{2}$ Main Center of Special Monitoring of the Ukrainian National Space Facilities Control and Test Center of the State Space Agency of Ukraine, Gorodok, Zhytomyr region, Ukraine, saan@ukr.net. Translated from Kibernetyka ta Systemnyi Analiz, No. 1, January-February, 2022, pp. 98-109. Original article submitted September 10, 2021.
} 
The above-mentioned classic publication [1] is based on preprint [5] with a slightly changed title. At the same time, preprint [5] is based on a talk given at conference [6]. A progress from a conference talk to a preprint and to a finite publication in a journal is a true and tested method of achieving high-quality practical and scientific results.

\section{PROBLEM STATEMENT}

To measure features of a pandemic, experts analyze and evaluate evolutionary models [7-12], in particular, the Bass diffusion model $[13,14]$. Remarks of experts on using the Bass model for modeling the spread of a pandemic focused on the importance of empirical data [14, 15], healthcare measures [14, 16], unidentified factors [14, 17-19], and organizational priorities [14,20,21]. Thus, the Bass model deserves a detailed study and its conclusions deserve a thorough justification.

The aim of this paper is to mathematically substantiate conclusions of the classical publication [1], as well as to apply diffusion processes not only for modeling the dynamics of infected individuals, but also for modeling the dynamics of vaccinated individuals according to real data. Note that in the Bass model, innovation is defined as consumption of a new product, which is a certain vaccine on the modern pharmaceutical market [16].

Let us propose a theoretical model and test it using empirical data of consumer durables, such as data on color television sales in the 1960s [1], to estimate initial purchase time periods of new products. The main model assumption is that these periods depend on the number of previous buyers. Let us identify an innovation and an imitation component in the behavior of the model. In accordance with historical data, the proposed model makes satisfactory predictions of peak sales and the moment the sales peaked.

The model can be applied in the case of increasing initial purchases of a wide range of characteristic new general product classes. Here, we distinguish between new product classes and new brands and models of old product classes that are in demand.

For new brands or products, exponential sales growth models are known till a certain asymptote. Here, sales grow rapidly till the moment they reach their peak, and stabilize later at a certain level below the peak. The stabilizing effect is explained by the relative growth in the reserve purchasing component of sales and the decrease in the initial purchase component.

Long-term forecasting of new product sales requires intuition, as well as information availability. This forecasting is mathematically similar to the infection models widely used in epidemiology [22, 23]. Assumptions about behavior are mostly similar to the theoretical concepts presented in scientific literature on reception and diffusion of new products [24], as well as to certain learning models [25]. Explicit behavioral assumptions differentiate the proposed model from models based on log-normal distribution and other sales growth models.

It is hard to tell assumptions apart from consequences necessary to assess time periods needed for reception of new ideas or products in general theories of reception and diffusion (dissemination) of new ideas or products in a social system [25].

If an individual decides to accept an innovation regardless of decisions of others in a social system, they are considered to be an innovator. Here, it can usually be assumed that innovators are the first ones to implement an innovation. Among these individuals, the following innovation adopter classes are distinguished according to the chronology of their decisions to adopt an innovation: (a) innovators, (b) the first adopters, (c) initial majority, (d) critical majority, and (e) waiting buyers.

In contrast to innovators, each adopter (of an innovation and a corresponding behavior) decides on whether to accept an innovation in a specific time period that depends on the ever increasing pressure from the social system on subsequent adopters in the case of increasing number of previous adopters. Classes from (b) to (e) can be grouped together as imitators in a mathematical statement. Unlike innovators, imitators depend on decision-making periods of other social system members concerning innovation reception. The first $2.5 \%$ of adopters can be innovators [25], who have certain social and psychological qualities and can engage with other innovators. Innovators are not dependent on decision-making periods of other social system members concerning innovation reception in a sense that the pressure on the innovator group decreases rather than increases in the case where the reproduction process unfolds. 


\section{MATHEMATICAL INNOVATION IMPLEMENTATION MODEL}

Effects of diffusion and displacement (replacement) have to be accounted for in the model of growth and decline in the demand for successive generations of technological innovations. A very famous model is Bass diffusion model of demand for initial purchases $[1,5,6]$. This model is behaviorally justified, which is consistent with social science research on reception (adoption and implementation) and innovation diffusion [25], while taking into account conditional probability of a reception event at a time $T$ if reception did not take place.

In the case of applying the theory to assessing initial purchase timing of a new consumer product, the following main assumption is brought forward: a probability $P(T)$ that an initial purchase takes place at the moment in time $T$ under the condition that no purchases took place before is a linear function of the quantity $Y(T)$ of previous buyers

$$
P(T)=p+\frac{q}{m} Y(T),
$$

where $Y(0)=0, P(0)=p$ is a constant, whose value reflects the importance of innovators in a social system (innovation ratio), $q / m$ is the linear function slope coefficient, and parameter $q$ is the imitation coefficient.

Seeing as the model parameters depend on the choice of timescale, such a time unit can be chosen, so that $p$ reflects

a fraction of innovators among all the adopters [25]. Product $\frac{p}{m} Y(T)$ reflects pressures acting on imitators in the case of increasing the number of previous buyers. For lower values of $T$, innovator influence is higher than that of imitators.

The above-mentioned main theory assumption can be formulated within a continuous model and a function of density of the moment of time of initial purchases. Here, the linear part of Eq. (1) is denoted by a probability.

During a lifecycle of a product, let $m$ of its initial purchases occur. As this product is rarely bought, its single sales number is equal to the number of its initial purchases during the part of a time interval, when there was no resale, i.e., from the beginning of product resale. General sales include both initial purchases and repurchases. Then, a fraction of previous buyers among the initial purchases at the moment in time $T$ of first initial purchases is

$$
F(T)=\frac{Y(T)}{m}, F(0)=\frac{Y(0)}{m}=0,
$$

and determines a fraction of the rest of buyers (potential market demand) as $1-F(T)$. Initial product purchases are made by innovators, who influence the first term of Eq. (1), and imitators, who influence the second term of Eq. (1), in a sense learning from the experience of previous buyers. Number of previous buyers $Y(T)$ does not influence the innovators during their first purchases.

Taking Eqs. (1) and (2) into account, the probability of product purchase at the moment in time $T$ under the condition that no purchases were performed before can be written as

$$
\frac{f(T)}{1-F(T)}=P(T)=p+q F(T),
$$

where $f(0)=P(0)=p, F(T)=\int_{0}^{T} f(t) d t, f(t)$ is the density function of time $t$.

From here, general number of purchases in the time interval $(0, T)$ is

$$
m \int_{0}^{T} f(t)=m F(T)=Y(T)=\int_{0}^{T} S(t) d t,
$$

where the sales density function can be represented as

$$
S(t)=m f(t)=m P(T)[1-F(T)]=P(T)[m-m F(T)]
$$

as a consequence of Eq. (3), and where, as a consequence of Eqs. (3) and (4), we obtain 


$$
\begin{gathered}
P(T)=p+q F(T)=p+\frac{q}{m} \int_{0}^{T} S(t) d t, m F(T)=Y(T)=\int_{0}^{T} S(t) d t ; \\
S(T)=\left(p+\frac{q}{m} \int_{0}^{T} S(t) d t\right)\left(m-\int_{0}^{T} S(t) d t\right) \\
=p m-p \int_{0}^{T} S(t) d t+q \int_{0}^{T} S(t) d t-\frac{q}{m}\left[\int_{0}^{T} S(t) d t\right]^{2}=p m+(q-p) Y(T)-\frac{q}{m}[Y(T)]^{2} ; \\
\frac{d F}{d t}=f(T)=\frac{S(T)}{m}=p+(q-p) \frac{Y(T)}{m}-q\left[\frac{Y(T)}{m}\right]^{2} \\
=p+(q-p) F(T)-q[F(T)]^{2} ; t+C=\int \frac{d F}{p+(q-p) F-q F^{2}} .
\end{gathered}
$$

Let us denote $a=-q, b=q-p$, and $c=p$. By taking into account that

$$
b^{2}-4 a c=(q-p)^{2}+4 p q=q^{2}-2 q p+p^{2}+4 p q=(p+q)^{2}>0,
$$

let us use the analytical expression of the integral of the rational function

$$
\begin{aligned}
& \int \frac{d F}{c+b F+a F^{2}}=\frac{1}{\sqrt{b^{2}-4 a c}} \ln \left|\frac{2 a F+b-\sqrt{b^{2}-4 a c}}{2 a F+b+\sqrt{b^{2}-4 a c}}\right| \\
= & \frac{1}{p+q} \ln \left|\frac{q-p-2 q F-q-p}{q-p-2 q F+q+p}\right|=\frac{1}{p+q} \ln \left|\frac{-2 p-2 q F}{2 q-2 q F}\right|,
\end{aligned}
$$

as well as the initial condition

$$
0+C=\frac{1}{p+q} \ln \left|\frac{-2 p-2 q \cdot 0}{2 q-2 q \cdot 0}\right|=\frac{1}{p+q} \ln \left|-\frac{p}{q}\right| .
$$

Thus, taking into account positivity of values $p, q$, and $F$, we obtain the following:

$$
\begin{gathered}
\frac{1}{p+q} \ln \left(\frac{p}{q}\right)+t=\frac{1}{p+q} \ln \left|-\frac{p}{q}\right|+t=\frac{1}{p+q} \ln \left|\frac{-p-q F}{q(1-F)}\right|=\frac{1}{p+q} \ln \left[\frac{p+q F}{q(1-F)}\right], \\
t=\frac{1}{p+q}\left\{\ln \left[\frac{p+q F}{q(1-F)}\right]-\ln \left(\frac{p}{q}\right)\right\}=\frac{1}{p+q} \ln \left[\frac{(p+q F) q}{q(1-F) p}\right]=\frac{1}{p+q} \ln \left[\frac{p+q F}{p(1-F)}\right], \\
\ln \{\exp [t(p+q)]\}=t(p+q)=\ln \left[\frac{p+q F}{p(1-F)}\right], \\
p \exp [t(p+q)]-p F \exp [t(p+q)]=p(1-F) \exp [t(p+q)]=p+q F, \\
p \exp [t(p+q)]-p=q F+p F \exp [t(p+q)]=F\{q+p \exp [t(p+q)]\}, \\
F=\frac{p\{\exp [t(p+q)]-1\}}{p \exp [t(p+q)]+q}<1, \\
F(T)=\frac{p\{\exp [T(p+q)]-1\}}{p \exp [T(p+q)]+q},
\end{gathered}
$$




$$
\begin{gathered}
f=\frac{d F}{d t}=\frac{p(p+q) \exp [t(p+q)]\{p \exp [t(p+q)]+q-p \exp [t(p+q)]+p\}}{\{p \exp [t(p+q)]+q\}^{2}} \\
=\frac{p(p+q)^{2} \exp [t(p+q)]}{\{p \exp [t(p+q)]+q\}^{2}}, \\
S(t)=m f=\frac{m p(p+q)^{2} \exp [t(p+q)]}{\{p \exp [t(p+q)]+q\}^{2}}, \\
\frac{d S}{d t}=m p(p+q)^{2} \frac{(p+q) \exp [t(p+q)]\{p \exp [t(p+q)]+q\}^{2}}{\{p \exp [t(p+q)]+q\}^{4}} \\
-m p(p+q)^{2} \frac{2\{p \exp [t(p+q)]+q\} p(p+q) \exp [t(p+q)]}{\{p \exp [t(p+q)]+q\}^{4}} \\
=m p(p+q)^{3} \exp [t(p+q)] \frac{\{p \exp [t(p+q)]+q\}\{q-p \exp [t(p+q)]\}}{\{p \exp [t(p+q)]+q\}^{4}} .
\end{gathered}
$$

Thus, for $q \geq p$, as well as for sufficiently small values of $t$, function $S(t)$ grows, reaching its maximum under the following condition:

$$
\begin{gathered}
0=q-p \exp [t(p+q)], \exp [t(p+q)]=\frac{q}{p}, t(p+q)=\ln \left(\frac{q}{p}\right), \\
T^{*}=t=\frac{\ln q-\ln p}{p+q} \geq 0 \text { for } q \geq p .
\end{gathered}
$$

Here, the imitation coefficient value has to be high. Then,

$$
\begin{gathered}
\exp [t(p+q)]=\exp \left[\ln \left(\frac{q}{p}\right)\right]=p^{-1} q, \\
S\left(T^{*}\right)=\frac{m p(p+q)^{2} p^{-1} q}{\left\{p p^{-1} q+q\right\}^{2}}=\frac{m(p+q)^{2} q}{4 q^{2}}=\frac{m(p+q)^{2}}{4 q} .
\end{gathered}
$$

Taking Eq. (5) into account, we obtain

$$
\begin{gathered}
\frac{m(p+q)^{2}}{4 q}=S\left(T^{*}\right)=p m+(q-p) Y\left(T^{*}\right)-\frac{q}{m}\left[Y\left(T^{*}\right)\right]^{2}, \\
m^{2}(p+q)^{2}=4 m^{2} p q+4 m q(q-p) Y\left(T^{*}\right)-4 q^{2}\left[Y\left(T^{*}\right)\right]^{2}, \\
Y\left(T^{*}\right)=\frac{4 m q(q-p) \pm \sqrt{D}}{8 q^{2}}=\frac{m(q-p)}{2 q} \geq 0,
\end{gathered}
$$

where the discriminant is equal to

$$
\begin{gathered}
D=16 m^{2} q^{2}(q-p)^{2}-16 q^{2}\left[m^{2}(p+q)^{2}-4 m^{2} p q\right] \\
=16 m^{2} q^{2}\left[(q-p)^{2}-(p+q)^{2}+4 p q\right] \\
=16 m^{2} q^{2}\left(q^{2}-2 q p+p^{2}-p^{2}-2 p q-q^{2}+4 p q\right)=0 .
\end{gathered}
$$


If $q<p$, then function $S(t)$ reaches its maximum for $t=0$ as follows:

$$
\begin{gathered}
S(0)=m f(0)=\frac{m p(p+q)^{2} \exp [0 \cdot(p+q)]}{\{p \exp [0 \cdot(p+q)]+q\}^{2}}=\frac{m p(p+q)^{2}}{(p+q)^{2}}=m p, \\
S(0)-S\left(T^{*}\right)=m p-\frac{m(p+q)^{2}}{4 q}=m \frac{4 p q-p^{2}-2 p q-q^{2}}{4 q}=-\frac{m}{4 q}(p-q)^{2} \leq 0 .
\end{gathered}
$$

As a rule, the ratio $p / q$ is nearing 0 for profitable products; therefore, the sales volume $S$ reaches its maximum, when the aggregate sales volume is nearing $m / 2$ and exceeding critical mass [26-29] as follows:

$$
Y\left(T^{*}\right)=\frac{m(q-p)}{2 q}=m\left(\frac{1}{2}-\frac{p}{2 q}\right) .
$$

\section{EXPECTED DURATION OF A NEW PRODUCT ENTERING THE MARKET}

In the case of arbitrarily choosing a buyer among $m$ buyers, who performs the initial product purchase at a certain moment in time, the expected duration of time $T$ for this purchase, taking into account Eq. (7), is

$$
\begin{gathered}
E(T)=\int_{0}^{\infty} t f(t) d t=\int_{0}^{\infty} \frac{t p(p+q)^{2} \exp [t(p+q)]}{\{p \exp [t(p+q)]+q\}^{2}} d t \\
=\int_{1}^{\infty} \frac{\ln z}{p+q} \cdot \frac{p(p+q)^{2} z}{(p z+q)^{2}} \cdot \frac{d z}{(p+q) z}=p \int_{1}^{\infty} \frac{\ln z}{(p z+q)^{2}} d z=\frac{1}{p} \int_{1}^{\infty} \frac{\ln z}{\left(z+p^{-1} q\right)^{2}} d z,
\end{gathered}
$$

where $z=\exp [t(p+q)], d z=(p+q) z d t$, and $\ln z=t(p+q)$. Using the expression

$$
\int \frac{\ln x}{(x+a)^{2}} d x=-\frac{\ln x}{x+a}+\frac{1}{a} \ln \frac{x}{x+a}
$$

for $a=p^{-1} q$, we obtain

$$
E(T)=\frac{1}{p}\left\{\frac{\ln 1}{1+p^{-1} q}-\frac{p}{q} \ln \frac{1}{1+p^{-1} q}\right\}=\frac{1}{q} \ln \left(1+p^{-1} q\right)=\frac{1}{q} \ln \left(\frac{p+q}{p}\right) .
$$

The product is received by innovators and imitators. At the beginning of the product reception process, a greater role is given to innovators, but later their influence decreases, while the influence of imitators increases. If the innovation is a consumer durable (for example, a television, a lawnmower, an air conditioner, a telephone, etc.), then sales $S(t)$ in a time period, when demand consists out of initial purchases, are proportional to innovation reception density function $f(t)$. If sales consist out of repurchases or multiple purchases of an innovative product, the levels of product reception and product sales are measured separately.

Theoretically, the distribution can be exponential or logistic distribution, as well as the Weibull distribution. Since exponential distribution is memoryless, it does not represent the essence of innovation spread. Applying logistic distribution and the Weibull distribution, results similar to the Bass model are obtained based on the data of not a few, but many observations. Resulting distribution (6) gives the best forecast for any number of observations. Taking into account diffusion models, Bass's logistical statement was somewhat modified and generalized. In the light of the nature of the data available for problems of (approximate) sales forecasting for most of new products and the (insufficient) amount of corresponding information, there are significant difficulties in reliable extrapolation of initial sales of a new product. To construct improved sales forecasting models, data constraints have to be accounted for. Bass's logistical statement $[1,5,6]$ reflects the essence of the innovation process, including diffusion and substitution effects. 


\section{ASSESSING MODEL PARAMETERS}

Let us turn from the basic continuous model (5) to a discrete analog

$$
S_{T}=a+b Y_{T-1}+c\left(Y_{T-1}\right)^{2},
$$

where $S_{T}$ is sales at the moment in time $T, Y_{T-1}=\sum_{t=0}^{T-1} S_{t}$ is cumulative sales performed until and including moment in time $(T-1), a$ is the assessment parameter of $p m, b$ is the assessment parameter of $(q-p)$, and $c$ is the assessment parameter of $\left(-m^{-1} q\right)$. From here,

$$
\begin{gathered}
b=q-p=-m c-m^{-1} a, c m^{2}+b m+a=0, \\
m=\frac{-b \pm \sqrt{b^{2}-4 a c}}{2 c}, \\
q=-m c=\frac{m\left(b \mp p \sqrt{b^{2}-4 a c}\right)}{2}, p=m^{-1} a=\frac{2 a c}{-b \pm \sqrt{b^{2}-4 a c}} .
\end{gathered}
$$

From (13), it follows that

$$
0=\frac{d S_{T}}{d Y_{T-1}}=b-2 c Y_{T-1}
$$

from here, as a result of Eq. (10), we obtain

$$
\begin{gathered}
Y_{T-1}^{*}=-\frac{b}{2 c}=\frac{m(q-p)}{2 q}=Y\left(T^{*}\right), \\
S_{T}\left(Y_{T-1}^{*}\right)=a+b Y_{T-1}^{*}+c\left(Y_{T-1}^{*}\right)^{2}=a-\frac{b^{2}}{2 c}+\frac{b^{2} c}{4 c^{2}}=a-\frac{b^{2}}{2 c}+\frac{b^{2}}{4 c}=a-\frac{b^{2}}{4 c} \\
=a-c\left(\frac{b}{2 c}\right)^{2}=p m+\frac{q}{m} \frac{m^{2}(q-p)^{2}}{4 q^{2}}=\frac{4 p m q+m(q-p)^{2}}{4 q} \\
=\frac{m\left(4 p q+q^{2}-2 q p+p^{2}\right)}{4 q}=\frac{m(p+q)^{2}}{4 q}=S\left(T^{*}\right)
\end{gathered}
$$

taking Eq. (9) into account. Thus, a conclusion can be made from equation $S_{T}\left(Y_{T-1}^{*}\right)=S\left(T^{*}\right)$ that the maximum sales number $S$ in the form of a time function coincides with the maximum sales number $S$ in the form of a cumulative sales function.

To test the Bass model, a regression analysis of parameter assessment was performed using annual time series data for 11 different consumer durables over different time periods, such as electric refrigerators from 1920-1940 (forecasting period from 1926 to 1940), freezers (forecasting period from 1947 to 1961), black and white televisions (forecasting period from 1949 to 1961), air conditioners from 1946-1961 (forecasting period from 1950 to 1961), dryers (forecasting period from 1950 to 1961), lawn mowers (forecasting period from 1949 to 1961), automatic coffee machines from 1948-1961 (forecasting period from 1951 to 1961), steam irons from 1949-1960 (forecasting period from 1950 to 1961), water softeners (forecasting period from 1950 to 1961), electric blankets from 1949-1961 (forecasting period from 1950 to 1961), and record players from 1952-1961 (forecasting period from 1953 to 1958). Time periods were determined by subjective assessment of product durability, as well as limited published data on write-offs and repurchase cycles. Here, such time periods were chosen, when 
repurchases were not important. The main sources of data is the Statistical Abstract of the United States, published by the United States Census Bureau and the United States Department of Commerce. This publication was annual from 1878 to 2011, describing the social, political, and economic conditions of the United States.

In addition to estimates $a, b$, and $c$ in regression dependence (11), for each product, their variances $\sigma_{a}, \sigma_{b}$, and $\sigma_{c}$, relations $\left(\sigma_{a}\right)^{-1} a,\left(\sigma_{b}\right)^{-1} b$, and $\left(\sigma_{c}\right)^{-1} c$, as well as the determination coefficient $R^{2}$ were calculated, respectively. Then, using relations (13), estimates $m, p$, and $q$ can be calculated. Regression estimate $c$ has a negative value for each product in accordance with the model's nature. Estimates $m$ take a plausible form for each product. One of the most important regression analysis results is the implicit estimate of the total number of initial purchases that are made during the life cycle of a product. For each product, the regression equation describes a general trend of the sales growth dynamics in a satisfactory manner, while trend deviations can be explained by short-term changes in income, which, in turn, correlate with economic growth or decline. For each product, the regression equation predicts the peak sales volume and its achievement moment in a satisfactory manner.

Correspondence of the regression equation to the actual sales is a relatively weak test of the model's efficiency, as it compares past observations with the equation estimates. A stronger test is the base model efficiency in accordance with time variables and certain regression estimates of parameter values, where, for each product, the peak sales moment can be forecast based on Eq. (8) based on estimates $m, p$, and $q$ and be compared with the actual time (time period is determined in a manner for the sales to exceed value $m p$ that is equal to $S(0)$ as a result of relation (11) for the first time). Peak sales volume can also be forecast based on Eq. (9) and be compared with the actual one. For electric refrigerators, the estimated peak sales moment was the longest (about 20 years), while the actual peak sales moment was not determined due to the Second World War. The shortest estimated peak sales moment was for record players (5 years), steam irons ( 7 years), and black and white televisions and dryers (8 years).

With estimates of parameters $m, p$, and $q$, we can forecast sales

$$
S(t)=\frac{m p(p+q)^{2} \exp [t(p+q)]}{\{p \exp [t(p+q)]+q\}^{2}}
$$

over a long time period and evaluate forecast accuracy for each product according to the determination coefficient value. The value was the lowest for black and white televisions due to significant (but short) trend deviations for 1950 and 1958. However, it did not affect the trend correctness in general, i.e., the Bass model is verified for the above-mentioned products. This model has played and continues to play an important role in development and implementation of new high-tech products.

New products during the pandemic are vaccines. To assess parameters of model (13), data from [30] on vaccine doses from COVID-19 administered per 100 people is used (total number of administered doses divided by the total population number). Each dose is calculated for vaccines that require multiple doses, and since the same individual can receive more than one dose, the number of doses per 100 people may exceed 100 [30]. Non-observable values that are generated, in particular, by empirical means [8] are presented by italics in Table 1 [8]. Data from Ukraine and Belarus was analyzed, taking into account the positive experience of the international project "Development of methods, algorithms, and intelligent analytical system for processing and analyzing various clinical and biomedical data with the aim to improve complex disease diagnosis" (M/99-2019 and M/37-2020 with support of the Ministry of Education and Science of Ukraine) performed at the V. M. Glushkov Institute of Cybernetics of the NAS of Ukraine together with United Institute of Informatics Problems of the NAS of Belarus (F19UKRG-005 with support of the Belarusian Republican Foundation for Fundamental Research) [31-34].

Table 1 presents Covid vaccine doses administered per 100 people in the weeks of the first half of 2021. Estimates of dependence parameters (13) calculated using MS Excel software are satisfactory for further practical observations in the second half of 2021. Table 2, respectively, presents estimates of parameters $a, b$, and $c$ of regression (12), values of parameters $m, p$, and $q$ from Eqs. (14) and (15), and values $S\left(T^{*}\right), Y\left(T^{*}\right), T^{*}$, and $E(T)$ from (9), (10), (8) and (12). 
TABLE 1

\begin{tabular}{|c|c|c|c|c|c|c|c|c|c|c|}
\hline \multirow{2}{*}{ Country } & \multicolumn{10}{|c|}{ Vaccine Doses in the First Half of 2021 } \\
\cline { 2 - 13 } & 23.02 & 2.03 & 9.03 & 16.03 & 23.03 & 30.03 & 6.04 & 13.04 & 20.04 & 27.04 \\
\hline Ukraine & & 0.02 & 0.05 & 0.18 & 0.36 & 0.53 & 0.73 & 0.92 & 1.09 & 1.28 \\
\hline Belarus & 0.22 & 0.22 & 0.22 & 0.28 & 0.39 & 0.58 & 0.85 & 1.43 & 2.24 & 2.75 \\
\hline \hline & & 4.05 & 11.05 & 18.05 & 25.05 & 1.06 & 8.06 & 15.06 & 22.06 & 29.06 \\
\hline Ukraine & & 1.74 & 2.02 & 2.19 & 2.26 & 2.40 & 3.04 & 3.58 & 4.01 & 4.42 \\
\hline Belarus & & 3.04 & 3.59 & 4.33 & 4.88 & 5.61 & 6.74 & 7.65 & 8.53 & 9.40 \\
\hline
\end{tabular}

TABLE 2

\begin{tabular}{|c|c|c|c|c|c|c|c|c|c|c|c|}
\hline \multirow{2}{*}{ Country } & \multicolumn{10}{|c|}{ Parameter Values } \\
\cline { 2 - 14 } & $R^{2}$ & $a$ & $b$ & $10^{6} c$ & $m$ & $q$ & $10^{6} p$ & $S\left(T^{*}\right)$ & $Y\left(T^{*}\right)$ & $T^{*}$ & $E(T)$ \\
\hline Ukraine & 0.73 & 7.85 & 0.11 & -33.16 & 3291 & 0.11 & 2384 & 94 & 1610 & 34 & 35 \\
\hline $\begin{array}{c}\text { Standard } \\
\text { Error }\end{array}$ & & 6.50 & 0.08 & 180.42 & & & & & & & \\
\hline \hline Belarus & 0.90 & 7.47 & 0.20 & -115.07 & 1739 & 0.20 & 4298 & 91 & 851 & 19 & 19 \\
\hline $\begin{array}{c}\text { Standard } \\
\text { Error }\end{array}$ & & 6.95 & 0.04 & 49.60 & & & & & & & \\
\hline
\end{tabular}

\section{CONCLUSIONS}

With proper organization of scientific and practical research, classical Bass model can be used to model stochastic processes describing the pandemic spread in other countries, as well as in regions and districts of Ukraine. This application requires careful examination of input information, verification and generation of input data, possible classical model modifications, development and justification of appropriate assessment methods, appropriate computer implementation of both algorithmic and program software, and statistical analysis of assessment results. Moreover, modern distributed information technologies of scientific and organizational activities of the NAS of Ukraine can be used to develop systemic methods and measures for healthcare [35].

\section{REFERENCES}

1. F. M. Bass, "A new product growth for model consumer durables,” Manage. Sci., Vol. 15, No. 5, $215-227$ (1969).

2. F. M. Bass, "The theory of stochastic preference and brand switching," J. of Marketing Research, Vol. 11, No. 1, 1-20 (1974).

3. F. M. Bass and J. A. Norton, "A diffusion theory model of adoption and substitution for successive generations of high-technology products," Manage. Sci., Vol. 33, No. 9, 1069-1086 (1987).

4. V. Mahajan, E. Muller, and F. Bass, "New product diffusion models in marketing: a review and directions for research," J. of Marketing, Vol. 54, No. 1, 1-26 (1990).

5. F. M. Bass, "A new product growth model for consumer durables," Institute Paper No. 175, Institute for Research in the Behavioral, Economic and Management Sciences, Herman C. Krannert Graduate School of Industrial Administration, Purdue University, Lafayette, IN (1967). 
6. F. M. Bass, "A dynamic model of Market share and sales behavior," in: Proc. Winter Conf. American Marketing Association, AMA, Chicago, IL (1963), pp. 263-276.

7. M. L. Gorbachuk and N. I. Pivtorak, "Solutions of evolution equations of parabolic type with degeneration", Differ. Uravn., Vol. 21, No. 8, 1317-1324 ((1985).

8. P. S. Knopov and O. N. Deriyeva, Estimation and Control Problems for Stochastic Partial Differential Equations, Springer, New York (2013).

9. O. G. Nakonechnyi, O. A. Kapustian, and A. O. Chikrii, "Approximate guaranteed mean square estimates of functionals on solutions of parabolic problems with fast oscillating coefficients under nonlinear observations," Cybern. Syst. Analysis, Vol. 55, No. 5, 785-795 (2019). https://doi.org/10.1007/s10559-019-00189-6.

10. P. S. Knopov, V. I. Norkin, K. L. Atoyev, V. M. Gorbachuk, V. S. Kyrylyuk, G. D. Bila, O. S. Samosonok, and O. V. Bogdanov, Some Approaches to the Use of Stochastic Models of Epidemiology to the Problem of COVID-19 [in Ukrainian], V. M. Gluskov Institute of Cybernetics, Kyiv (2020).

11. A. A. Vagis, A. M. Gupal, and N. A. Gupal "Determination of groups of risks at the diseases COVID-19," Cybernetics and Computer Technologies, No. 3, 25-31 (2020).

12. S. Yakovlev, K. Bazilevych, D. Chumachenko, T. Chumachenko, L. Hulianytskyi, I. Meniailov, and A. Tkachenko, "The concept of developing a decision support system for the epidemic morbidity control," CEUR Workshop Proceedings, Vol. 2753, 265-274 (2020).

13. K. Gurumurthy and A. Mukherjee, "The Bass model: A parsimonious and accurate approach to forecasting mortality caused by COVID-19,” Intern. J. of Pharmaceutical and Healthcare Marketing, Vol. 14, No. 3, 349-360 (2020).

14. G. Allenby, L. Gengler, A. Sood, G. J. Tellis, and R. S. Winer, "Commentaries: The Bass model: A parsimonious and accurate approach to forecasting mortality caused by COVID-19," Intern. J. of Pharmaceutical and Healthcare Marketing, Vol. 14, No. 3, 361-365 (2020).

15. V. Gorbachuk and S. Gavrilenko, "Analysis for dynamics of COVID-19 spreading in Ukraine and neighboring countries on May 1-10, 2020," in: Proc. VIII Intern. Sci. Internet Conf. "Global and Regional Problems of Informatization in Society and Nature Using '2020” (Kyiv, Ukraine, May 14-15, 2020), National University of Life and Environmental Sciences of Ukraine, Kyiv (2020), pp. 56-60.

16. V. M. Gorbachuk and G. O. Shulinok, "Modeling of behavior for a pharmaceutical firm," Teoriya Optymal'nykh Rishen', 147-153 (2017).

17. V. M. Gorbachuk, "An asymmetric Cournot-Nash equilibrium under uncertainty as a generalized Cournot-Stackelberg-Nash equilibrium, ” Cybern. Syst. Analysis, Vol. 43, No. 4, $471-477$ (2007). https://doi.org/10.1007/s10559-007-0073-3.

18. Y. Ermoliev, T. Ermolieva, T. Kahil, M. Obersteiner, V. Gorbachuk, and P. Knopov, "Stochastic optimization models for risk-based reservoir management," Cybern. Syst. Analysis, Vol. 55, No. 1, 55-64 (2019). https://doi.org/10.1007/s10559-019-00112-z.

19. V. Gorbachuk, Y. Ermoliev, A. Zagorodniy, V. Bogdanov, T. Ermolieva, E. Rovenskaya, N. Komendantova, O. Borodina, P. Knopov, V. Norkin, and A. Gaivoronski, "Iterative stochastic quasigradient procedures for robust estimation, machine learning and decision making problems," in: Proc. 31st Europ. Conf. on Operational Research (Athens, Greece, July 11-14, 2021), The Association of European Operational Research Societies (2021), pp. 184-185.

20. V. M. Gorbachuk, "Generalized Cournot-Stackelberg-Nash equilibrium,” Cybern. Syst. Analysis, Vol. 42, No. 1, 1-7 (2006). https://doi.org/10.1007/s10559-006-0033-3.

21. V. Gorbachuk, M. Dunaievskyi, and S.-B. Suleimanov, "Modeling of agency problems in complex decentralized systems under information asymmetry," in: 2019 IEEE Intern. Conf. on Advanced Trends in Information Theory (ATIT) (Kyiv, Ukraine, Dec. 18-20, 2019), IEEE (2019), pp. 449-454.

22. M. S. Bartlett, Stochastic Population Models in Ecology and Epidemiology, Methuen, London (1960).

23. M. S. Bartlett, An Introduction to Stochastic Processes: With Special Reference to Methods and Applications, 1st ed., Cambridge University Press, New York (1955).

24. E. Mansfield, Industrial Research and Technological Innovation: An Econometric Analysis, Norton, New York (1968).

25. E. M. Rogers, Diffusion of Innovations, 5th ed., Free Press, New York (2003). 
26. Y. Krivonos, V. Gorbachuk, W. Wojcik, and S. Smailova, "Time series regression and Granger causality," in: W. Wojcik and J. Sikora (eds.), Current Problems in Information and Computational Technologies, Vol. 2, Politechnika Lubelska, Lublin (2012), pp. 7-49.

27. V. M. Gorbachuk, "Determining the critical mass for distribution of network products," Scientific and Technical Information, No. 4, 50-55 (2013).

28. V. Gorbachuk and B. Chumakov, "A computable critical mass on market of new network product," in: Transport Systems and Logistics, Academia de Transporturi, Informatică și Comunicaţii, Chisinau (2013), pp. 272-281.

29. V. Gorbachuk, M. Dunaievskyi, and A. Syrku, "Epidemic effects in network industries," in: Intern. Conf. on Software Engineering: Proceedings (Kyiv, Ukraine, April 12-14, 2021), National Aviation University, Kyiv (2021), pp. 68-72.

30. E. Mathieu, H. Ritchie, E. Ortiz-Ospina, M. Roser, J. Hasell, C. Appel, C. Giattino, and L. Rodes-Guirao, "A global database of COVID-19 vaccinations," Nat. Hum. Behav., Vol. 5, 947-953 (2021).

31. T. O. Bardadym, V. M. Gorbachuk, N. A. Novoselova, S. P. Osypenko, and V. Yu. Skobtsov, "Intelligent analytical system as a tool to ensure the reproducibility of biomedical calculations," Artificial Intelligence, No. 3, 67-81 (2020).

32. N. A. Novoselova, V. Yu. Skobtsov, I. E. Tom, T. A. Bardadym, V. M. Gorbachuk, and S. P. Osypenko, "Modern options for development and organization of intelligent analytical systems, in: Ideas of Academician V. M. Glushkov and Modern Problems of Theoretical Cybernetics: Proc. IX All-Ukrain. Sci. And Pract. Conf. "Glushkov Readings," Taras Shevchenko National University of Kyiv, Kyiv (2020), pp. 113-116.

33. V. Gorbachuk, V. Skobtsov, and I. Tom, "Economic aspects of health care in the information age," in: N. Dubrovina and S. Filip (eds.), National Health as Determinant of Sustainable Development of Society, School of Economics and Management in Public Administration, Bratislava, Slovakia (2021), pp. 697-720.

34. T. Bardadym, V. Gorbachuk, N. Novoselova, S. Osypenko, V. Skobtsov, and I. Tom, "On biomedical computations in cluster and cloud environment," Cybernetics and Computer Technologies, No. 2, 76-84 (2021).

35. V. Gorbachuk, S. Gavrilenko, G. Golotsukov, and D. Nikolenko, "To digital technologies of patent processing for development of critical products," in: Proc. 2021 Intern. Conf. on Information and Digital Technologies (IDT) (Zilina, Slovakia, June 22-24, 2021), IEEE (2021), pp. 131-141. 